\title{
Educación, Derechos Humanos y Shoá: Una Aproximación desde la experiencia teórico práctica
}

\author{
Education, Human Rights and Shoah: An Approach from theoretical and practical \\ experience
}

\section{Resumen}

Lorena González

Escuela E 50- Republica de Israel leonor1973@gmail.com

El presente artículo señala la importancia de incorporar dentro del currículum de formación ciudadana en educación básica la enseñanza de la Shoá como un recurso pedagógico que permita por una parte enfatizar la pedagogía de la memoria a través del relato vivencial de quienes fueron víctimas de esta; establecer un análisis que permita a los estudiantes comprender la importancia de una educación basada en derechos humanos; relevar el valor del paradigma de inclusión como un componente vital en la conformación de sociedades interculturales; y por último, entender los peligros que genera formar ciudadanos apáticos, abúlicos, indiferentes y poco informados en sociedades democráticas en constante flujo de cambios.

Palabras claves: Educación, Derechos Humanos, Shoá, Pedagogía, Ciudadanía.

\begin{abstract}
The present article points out the importance of incorporating the teaching of the Shoah as a pedagogical resource within the curriculum of citizen education in basic education that allows, on the one hand, to emphasize the pedagogy of memory through the experiential account of those who were victims of it; establish an analysis that allows students to understand the importance of an education based on human rights; to highlight the value of the inclusion paradigm as a vital component in shaping intercultural societies; and finally, to understand the dangers generated by forming apathetic, abulic, indifferent and uninformed citizens in democratic societies in constant flux of change.
\end{abstract}


Keywords: Education, Human Rights, Shoah, Pedagogy, citizenship

\section{Introducción}

La búsqueda de una respuesta que permita describir las razones por las cuales algunas sociedades han establecido formas de validación de poder que traspasan las libertades individuales es variada. Desde una óptica económica, el fin parece justificarse en el rechazo de minorías que impiden el crecimiento y el progreso del desarrollo. Esta amenaza civil es responsabilizada de la o las crisis internas por lo que se determina excluirlas y para ello no interesa el cómo sólo el por qué.

También existen aquellas manifestaciones que promueven descentralizar los focos de poder fáctico para ser traspasados a quienes no lo tienen por medio de la instrumentalización de la violencia, el caos y la opresión. Por ende, el desconocimiento y la falta de información por parte de la población generan un vacío de probeta capaz de cultivar crímenes de lesa humanidad jamás pensados.

Es en este punto que la mirada de los expertos debiese cuestionar que ocurre a nivel educativo con estas sociedades. Por ello, la reflexión debiese estar centrada en las garantías que el estado de derecho otorga a sus ciudadanos.

Si la mirada país al día de hoy ha propiciado mecanismos que han permitido instalar políticas educativas centradas en el aprendizaje de formas de convivencia cívicas centradas en el respeto, la validación del otro como un legítimo otro, la construcción del diálogo como herramienta de generación de espacios y nuevas ideas, también debiese velar por la puesta en práctica de relatos de memoria capaces de generar aprendizajes que trasciendan la realidad nacional.

Para muchos, la formación entregada en enseñanza básica representa los pilares valóricos constitutivos que sustentan el futuro del país. Por lo mismo, cabe cuestionarse ¿Cuál es la responsabilidad de las instituciones educativas de enseñanza básica en la transmisión de la 
memoria como precedente que sustente una educación para la paz basada en derechos humanos y Shoá?

Sin duda alguna, el Holocausto marca un antes y un después en la historia de la humanidad. La planificación sostenida de un acto criminal que involucró el exterminio de 6 millones de judíos y casi dos millones de niños y niñas no tiene precedente. Sin embargo, la no existencia previa de un acto genocida de estas características sentó las bases para que otros hechos similares puedan tomar lugar.

La acción de aniquilación Nazi dejó una escuela que puede ser replicada por cualquier líder en cualquier momento histórico, presente o futuro. Por esta razón se hace tan importante incorporar dentro del currículum de formación ciudadana en educación básica la enseñanza de la Shoá como un recurso pedagógico que permita por una parte enfatizar la pedagogía de la memoria a través del relato vivencial de quienes fueron víctimas de esta; establecer un análisis que permita a los estudiantes comprender la importancia de una educación basada en derechos humanos; relevar el valor del paradigma de inclusión como un componente vital en la conformación de sociedades interculturales; y por último, entender los peligros que genera formar ciudadanos apáticos, abúlicos, indiferentes y poco informados en sociedades democráticas en constante flujo de cambios.

Por todo lo anteriormente expuesto, la presente monografía busca a) establecer, a través de una experiencia pedagógica, lineamientos pedagógicos para el abordaje de la temática de derechos humanos y Shoá en el currículum de 4to a 8vo básico; b) describir estrategias metodológicas y didácticas para el abordaje de la temática de derechos humanos y Shoá en el currículum de 4to a 8vo básico y c) analizar el impacto de la experiencia pedagógica en una comunidad educativa.

En la consecución de los objetivos planteados, primeramente se presenta una descripción de la pedagogía de la memoria como un recurso educativo; en segundo lugar, se establece un análisis de abordaje de la temática de derechos humanos y Shoá en la formación de estudiantes de 4to a 8vo básico. Finalmente se describe una propuesta basada en didácticas integradas para la implementación de Shoá en el currículum de 4to a 8vo básico. 


\section{Memoria y legado: Lo que los pueblos no deben olvidar a través de la pedagogía de la memoria.}

¿Por qué una educación basada en memoria y legado? En la actualidad, se han generado diversas aproximaciones frente a lo que significa la incorporación de la memoria cómo recurso pedagógico para implementar en el currículum la temática de Derechos Humanos y su ejecución en aula a través de la interacción del núcleo pedagógico. Por consiguiente, el fin último se centra en la transmisión de experiencias que permitan poner en práctica la consigna del nunca más y así proveer a las generaciones futuras de conocimiento basado en el atropello y violación de la dignidad humana con sustrato en el no respeto y no reconocimiento del otro como un legítimo otro con derechos estatuidos tanto por la constitución de la República de Chile como por organismos internacionales.

Desde una mirada educativa, se puede interpretar este término como una construcción que además de traer a la conciencia algo que nos ha ocurrido, también permite "'realizar el ejercicio de integrar y organizar una serie de eventos unidos por un cierto significado." La memoria en este caso representa una conformación sico-emocional capaz de generar aprendizaje a través de la recreación de contextos concretos y tangibles. Por lo mismo, la naturaleza epistemológica y axiológica de ella la convierte en una poderosa herramienta para el desarrollo del pensamiento y el análisis crítico del accionar social.

La consideración de la memoria como propuesta reflexiva que pueda promover una educación transformadora, se apoya en diferentes fundamentos históricos y epistemológicos. $^{2}$

Esto significa por una parte realizar el ejercicio de reconocer a los sujetos participantes como seres históricos, insertos en el tiempo presente, instalados para enfrentar procesos de transformación y coyunturas existenciales. Por otro, implementar a través de la pedagogía

\footnotetext{
${ }_{1}^{1}$ Peña, 2013, citado en Scavino, Pedagogía de la Memoria y Educación para el Nunca Más, p.73.

${ }^{2}$ Mediante esta cita, se quiere enfatizar el hecho que la autora destaca la memoria como un acto reivindicativo del nunca más.
} 
de la memoria la validación del presente como un acto histórico que debe ser reproducido como tal dado que:

se trata de transmitir a través de la memoria una ética de la atención, una actitud de cuidado con los Otros y Otras, una modalidad para que las jóvenes generaciones sean más atentas que sus mayores en el respeto a la dignidad humana. No es sólo un esfuerzo por no olvidar la historia para no tener que repetirla, como tampoco recordar el sufrimiento pasado de la humanidad con la intención oculta de una venganza..." (Barcena \& Mélich 2000: 22). ${ }^{3}$

Para poder llevar a cabo esta apuesta pedagógica, no solamente debe existir una propuesta de carácter curricular implícita en las políticas públicas educativas, sino que también debe ser parte de la línea de formación docente a nivel inicial en todas las carreras relacionadas con el ámbito pedagógico y de perfeccionamiento de prácticas pedagógicas en el caso de profesionales de la educación en actual ejercicio.

Sacavino (2015), reconoce tres dimensiones y fundamentos epistemológicos que deben ser considerados al momento de implementar una pedagogía de la memoria y de formación docente en memoria: a) reconocimiento de los sujetos como seres históricos, b) historicidad de la configuración de nuestras sociedades desde la mirada de los derechos humanos, y c) la relación existente entre memoria e interculturalidad, con foco en la valoración de la diversidad socio-político-cultural. La responsabilidad del desarrollo de una educación para y por la paz en conjunto con los lineamientos de formación ciudadana en un estado de derecho debe estar enmarcada en estos conceptos.

Citado en Sacavino, Pedagogía de la Memoria y Educación para el Nunca Más, para la Construcción de la Democracia, p.73. 
A modo de ejemplo, Magendzo y Toledo $(2009)^{4}$ realizaron un estudio centrado en la temática de derechos humanos y su cobertura curricular en la asignatura de historia y ciencias sociales en segundo año medio. El objeto de estudio se centró "en las formas y modalidades de enseñanza y aprendizaje de la subunidad "Régimen Militar y transición a la democracia” Dentro de la propuesta investigativa y reflexiones presentadas en este trabajo se plantea "que la educación en Derechos Humanos se convierte en un vigilante del recuerdo" enfatizando la necesidad de cautelar que en el futuro no se repitan hechos tan deleznables como los vividos. Al mismo tiempo, se estipula que la vinculación de la educación basada en derechos humanos con la historia reciente le permite comprender a los estudiantes como el presente responde a hechos temporales vivenciados y cómo estos pueden entregar una mirada de futuro más esperanzadora.

Por lo mismo, sin memoria, las estrategias de enseñanza en derechos humanos se hacen vulnerables y quebradizas. El acto de memoria es un proceso de características subjetivas que se movilizan a partir de experiencias materiales, afectivas y simbólicas, susceptible de ser manipulada y abierta a transformaciones. El pasado adquiere sentido "desde el momento que se evoca desde el presente con una mirada al futuro" (Sacavino, 2015). Si bien, existe una diferencia de significancia entre historia y memoria, no se puede negar que la historia nace y se apoya en la memoria (Nora, 2009) ${ }^{5}$

Los actos de memoria permiten una consecución de legado histórico para la preservación y el resguardo de los derechos ciudadanos. La responsabilidad de transmitir este legado recae en la educación brindada en los establecimientos como entidades garantes del ejercicio democrático de la formación ciudadana, por lo tanto la incorporación del concepto de memoria como herramienta pedagógica debe estar centrado en la memoria como referente individual, social y narrativa. Al ser la memoria un acto de restitución del pasado hay ciertos hechos que son convocados y otros no por lo tanto la memoria y el olvido también forman parte de la valiosa experiencia de reconstrucción colectiva.

Abraham Magendzo , Ma Isabel Toledo, Educación en Derechos Humanos: Currículum Historia y Ciencias Sociales del $2^{\circ}$ año de Enseñanza Media. Subunidad "Régimen Militar y Transición a la Democracia", p.139.

${ }^{5}$ Citada en Izquierdo, El Lugar de la Memoria en Educación Pública. Una Política para el Olvido, p.36. 
Sin embargo, se debe tener presente que su uso no debe ser sobredimensionado dado que el mismo acto conmemorativo del recuerdo puede generar estereotipos desgastantes "cuando las narrativas se repiten en forma mecánica" ${ }^{6}$ (Levi, 1989).

\section{Derechos Humanos y Shoá: su importancia en la formación de estudiantes de enseñanza básica de de 4 to a 8 vo básico.}

En el año 1948 se firma la Declaración de los Derechos Humanos como una respuesta de preservación de la dignidad del ser humano frente a actos que involucraron crímenes de lesa humanidad. Si se considera lo planteado en el preámbulo establecido en ésta cabe preguntarse por qué, aun cuando, después de 69 años de haberse establecido un marco regulador que estipula los lineamientos que rigen el comportamiento del hombre para y con el hombre, hechos de características similares se repiten bajo la responsabilidad de estados garantes de la seguridad y bienestar de su población.

Considerando que la libertad, la justicia y la paz en el mundo tienen por base el reconocimiento de la dignidad intrínseca y de los derechos iguales e ineludibles de todos los miembros de la familia humana ${ }^{7}$

Desde el retorno a la democracia, en Chile, enormes esfuerzos y consensos se han desplegado para poder insertar en el currículum escolar acciones tendientes al abordaje pedagógico de los Derechos Humanos y su relevancia en la formación ciudadana. Esto significa que se da por hecho que la educación formal, escolar, es la responsable de la transmisión del conocimiento histórico relacionado con esta materia. Por ello, la Ley General de educación en su artículo segundo señala que:

\footnotetext{
${ }^{6}$ Citado en Izquierdo, El lugar de la Memoria en Educación Pública. Una Política para el Olvido, p. 36.

${ }^{7}$ Declaración Universal de los Derechos Humanos. < http://www.derechoshumanos.net $>, 10$ de diciembre de 1948.
} 
La educación es el proceso de aprendizaje permanente que abarca las distintas etapas de la vida de las personas y que tiene como finalidad alcanzar su desarrollo espiritual, ético, moral, afectivo, intelectual, artístico y físico, mediante la transmisión y el cultivo de valores, conocimientos y destrezas. Se enmarca en el respeto y valoración de los derechos humanos y de las libertados fundamentales, de la diversidad multicultural y de la paz y de nuestra identidad nacional, capacitando a las personas para conducir su vida en forma plena, para convivir y participar en forma responsable, tolerante, solidaria, democrática y activa en la comunidad y para trabajar y contribuir al desarrollo del país. ${ }^{8}$

Estos consensos se han visto regulados por las negociaciones políticas referidas a la naturaleza propia del abordaje del currículum nacional post dictadura y los conflictos suscitados de ello se refieren a qué temáticas abordar y cómo realizarlo. Magendzo y Toledo (2009) señalan que la discusión del rol del currículum en este aspecto lo sitúa en diversas posiciones según su naturaleza y esto define la forma como se convierte posteriormente en un acto pedagógico. De esta manera, cuando se aborda al currículum y el poder como un acto político y técnico pedagógico también se relaciona con la enseñanza de los Derechos Humanos y el poder y lo que ello encierra a la hora de implementarlo. Si se visualiza al currículum como un agente negociador de saberes, también se debe emplear esta lógica para entender la didáctica presente en la transmisión de estos derechos.

Por lo mismo, no se puede descartar la participación de poderes fácticos a la hora del diseño curricular $^{9}$, por ende es sumamente necesario tener claridad de los precedentes históricos que mueven la conformación de una nación y las acciones concatenadas a nivel mundial. Esto supone desarrollar una mirada ética basada en un constructo moral que finalmente permita generar actos pedagógicos formales centrados en el resguardo de los

\footnotetext{
${ }^{8}$ Ley 20.370. General de Educación. [en línea]< http://www.leychile.cl>, Santiago, Chile, 12 de septiembre de 2009.

9 Abraham Magendzo, Ma Isabel Toledo, Educación en Derechos Humanos: Currículum Historia y Ciencias Sociales del $2^{\circ}$ año de Enseñanza Media. Subunidad "Régimen Militar y Transición a la Democracia, 2009.
} 
derechos civiles, democráticos y políticos. No se puede pensar en un estado de derecho que omita hechos históricos y actos de memoria por no representar las corrientes de liderazgo de turno. Así como tampoco se puede utilizar el abordaje de los Derechos Humanos en educación como un vehículo para polarizar las miradas del accionar político.

Es en esta línea entonces que se diseña un marco curricular nacional que presenta en la asignatura de Historia, Geografía y Ciencias Sociales la incorporación desde primero a quinto básico de una unidad específica referida a Derechos Humanos y Actitudes Cívicas las que desglosadas en orden progresivo y por nivel, y de acuerdo al desarrollo de competencias y objetivos de aprendizaje se comprenden de la siguiente manera: a) reconocimiento de símbolos e identidad nacional, b) valoración de expresiones propias de la cultura chilena, c) valoración de los deberes y responsabilidades en la vida de la comunidad, d) adquisición de herramientas que permitan la participación ciudadana en una comunidad, e) incorporación de la temática de Derechos Humanos frente a las actitudes cívicas como sujetos de derecho.

La incorporación de este Eje de Formación Ciudadana en los primeros niveles de escolaridad promueve una apropiación activa de los conceptos claves de ciudadanía para así apropiarse de las habilidades que se ponen en juego a la hora de conformar una sociedad más diversa basada en derechos y deberes cívicos.

Para el nivel de sexto año básico el programa enfatiza el desarrollo de competencias ciudadanas y respeto por la valoración y diversidad humana a través de la búsqueda del reconocimiento de ideales y prácticas que sustentan el estado de derecho, la participación democrática activa y responsable. La adquisición de estas herramientas de formación ciudadana se complementan con aquellas referidas al reconocimiento de las instituciones que son las bases de la organización del Estado. De igual manera, la incorporación de estos elementos en las cuatro unidades pilares del currículum de 6to básico promueve que los estudiantes sean capaces de "reconocer la riqueza de la diversidad y de comprender que el 
género, el origen étnico, las creencias o el nivel socioeconómico, entre otras, no deben ser objeto de discriminación o de diferencia de oportunidades"

Consecutivamente, los programas de estudio de séptimo básico y octavo básico respectivamente, presentan una óptica de formación en Derechos Humanos que se centra en el desarrollo de competencias ciudadanas basada en el respeto a través de la formación de una conciencia ética y la preservación del bien común y medio ambiental. El objetivo central es la búsqueda del desarrollo del conocimiento frente al establecimiento de la democracia representativa actual, y sus características cómo sistema político "susceptible de avances y retrocesos." ${ }^{\prime 1}$ Esta propuesta valida el respeto por la diversidad y la resolución de conflictos basada en el diálogo, la argumentación, el respeto por el otro y la validación del otro desde sus ideas y conformación socio-cultural.

Por lo tanto, esta conformación curricular ha establecido los nexos que permiten a las instituciones educacionales a cargo de la formación básica o primaria del país relevar la importancia de una educación que promueva el desarrollo del pensamiento crítico, la apropiación de una identidad conformada en derechos y deberes en la cual prevalezca la protección y resguardo de todo individuo sin importar etnia, credo, postura política y condición sexual. Esto lleva a visualizar al estudiante como un sujeto empoderado de su rol ciudadano, consciente del momento histórico en el que está inserto, capaz de visualizarse como un agente de cambio y constructor de nuevas realidades democráticamente.

Por esta razón se aprueba la ley 20.911 en el año 2016 que convoca a los establecimientos educacionales reconocidos por el Estado a implementar en todos los niveles educativos un Plan de Formación Ciudadana. El sentido primario de esta ley se enmarca en brindar a los estudiantes de las herramientas necesarias para: "asumir una vida responsable en una sociedad libre y de orientación hacia el mejoramiento integral de la persona humana. ",12

\footnotetext{
${ }^{10}$ Mineduc, Historia, Geografía y Ciencias Sociales. Programa de Estudio Sexto Año Básico. [en línea]. <http://www.curriculumenlineamineduc.cl/605/articles-18973_programa.pdf.> [consulta: 10 de diciembre 2017]

${ }^{11}$ Mineduc, Eje de Formación Ciudadana. [en línea]. < https://formacionciudadana.mineduc.cl/formacionciudadana-curriculum/modulos-didacticos-eje-formacion-ciudadana/> [consulta: $10 \mathrm{de}$ diciembre de 2017]

${ }^{12}$ Ley 20.911 Plan de Formación Ciudadana para los Establecimientos Educacionales Reconocidos por el Estado. [en Línea]. 〈https://www.leychile.cl/Navegar?idNorma=1088963>. Santiago, Chile, 02 de abril de 2016. [consulta: 10 de diciembre de 2017].
} 
Así mismo, la ley enfatiza el poder emanado del ejercicio democrático, la comprensión y compromiso de las futuras generaciones con los derechos humanos reconocidos en la Constitución Política y en los tratados internacionales suscritos y ratificados por el país a través del fomento de la valoración de la diversidad social y cultural así como también la tolerancia y el pluralismo; la participación en temas de interés público y el desarrollo de una cultura democrática y ética en la escuela.

Esto ratifica el sentido de generar acciones cívicas educativas capaces de revertir el pasado que ha acompañado la conformación de nuestra historia y por qué no decirlo también el presente de ella según la perspectiva que se emplee.

Entonces ¿por qué es importante incorporar la temática de Shoá para enfatizar el trabajo de análisis de Derechos Humanos en los niveles de cuarto a octavo básico y generar aprendizajes? Primero que todo es menester indicar que el Holocausto Judío o Shoá "fue un genocidio, pero de tipo especial y sin precedentes. ${ }^{, 13}$ No existe en la historia de la humanidad ninguna acción comparable que involucre el levantamiento del hombre en contra del hombre con el objetivo de erradicar de la tierra a un grupo humano sólo por el hecho de ser judíos. Históricamente hablando, nos referimos a un asesinato planificado, a una ejecución masiva como respuesta de una estrategia de aniquilación.

Según Gutman (2003), existen dos razones que explican el interés por indagar acerca de este fenómeno histórico y que pueden sentar las bases de la respuesta a la pregunta convocada:

La primera, es la universalidad del Holocausto que incluyó fenómenos como ideología totalitaria, estado moderno, mecanismos burocráticos de dominio, sistemas bélicos sofisticados, campos de concentración, etc. La otra causa, contrapuesta a su universalidad, es la particularidad de las víctimas del Holocausto, los judíos y la violencia de los contenidos políticos, raciales y

\footnotetext{
${ }^{13}$ Bauer, Yeuda, Reflexiones sobre el Holocausto. 2013.
} 
antisemitas proyectados sobre los mismos como consecuencia de su singularidad histórica en el mundo occidental. ${ }^{14}$

La Shoá se enmarca en un período de la historia moderna de crisis económica y política. Hitler asciende al poder en 1933, momento en el cual, la debacle económica ocurrida por la gran depresión tenía sumidos a los alemanes en un profundo estado de incertidumbre. La inseguridad acarreada por la cesantía de millones sumada a una autoestima derrotada producto de la Primera Guerra Mundial y la desconformidad con el gobierno de Weimar propician las condiciones para la elección de un líder que desde hacía 12 años había propuesto en sus escritos y discursos públicos que los culpables del fracaso económico y la desgracia de Alemania y de su situación actual eran los judíos.

A raíz de esto, la proposición del partido Nazi en 1920 señala que ningún judío puede ser ciudadano y que ningún no ciudadano puede ejercer cargos públicos. Además, esta enfatiza que si el estado no puede alimentar a toda su población, los no ciudadanos deben ser expulsados del Reich.

Posteriormente, con la promulgación de las Leyes de Nuremberg en 1935 que dictaminan la Ley de Ciudadanía del Reich y la Ley de Protección de la Sangre y el Honor Alemán comienza una persecución radical y planificada que se manifiesta a través da la prohibición de matrimonios entre alemanes y judíos, establecer comercio entre alemanes y judíos, la contratación por parte de judíos de empleados alemanes.

Así mismo, el descredito y descalificación peyorativa sentada en el uso de estereotipos se convierten en propaganda explícita a cargo de los medios de comunicación y del currículum educativo. Paralelamente se dictaminan ordenes de aislamiento y visibilización de los judíos por medio del uso de distintivos que los identificaran como tal; se establecen normativas que regulan el uso de espacios públicos por parte de los judíos; comienzan las manifestaciones de ataques civiles por medio de la quema de propiedades y destrucción del patrimonio; se valida el aislamiento de familias, despojo de valores y pertenencias a través de la creación de guetos. Se dicta una norma de fiscalización y control de la alimentación a

${ }^{14}$ Gutman, Israel, Holocausto y Memoria, 2013. 
través de medidas de racionamiento alimenticio. Se lleva a cabo la separación de las familias para enviar a sus miembros a campos de concentración y finalmente se ejecuta el asesinato planificado a través de la Solución Final en los campos de exterminio y la operación de aniquilación masiva llevada a cabo por los equipos móviles de matanza Einsatzgruppen.

Esta secuencia de hechos que puede ser interpretada por el lector como un resumen en la consecución de situaciones con una connotación lejana, encierra un acto de memoria que desafía a las actuales políticas públicas educativas a relevar la educación en derechos humanos no solamente desde una óptica del deber ser sino que también desde la incorporación en el currículum de situaciones de análisis reales, concretas que son parte de la conformación del ser humano actual y que han marcado el destino de toda la humanidad.

Al respecto, educar a los estudiantes y docentes en Shoá hoy día permite acercarlos al estudio del paradigma de la inclusión, de la exclusión, la exclusión social, la integración y la segregación social en su sentido etimológico y semántico. El currículo actual pone de relieve la formación de una sociedad más inclusiva, sin embargo pareciera que el término inclusión se relaciona con una concepción de igualdad mal entendida que va en desmedro de la conformación de sociedades abiertas a las diferencias. De hecho, si se analiza el término inclusión y se toma la Shoá como referente se puede plantear que uno de los componentes distintivos de los Nazis fue la construcción de un sistema totalitario basado en estereotipos y en discriminación. ¿Acaso no estamos hoy como país vivenciando un momento intercultural importante? ¿Qué ocurriría si se gestara un movimiento de discriminación a las minorías migrantes? ¿Cómo podemos evitar la xenofobia en nuestras aulas?

A través de la educación en Shoá también se puede analizar con los estudiantes los factores que finalmente llevan a una sociedad a ser actores perpetradores y cómplices pasivos de situaciones límites que llevan al ser humano a actos de deshumanización. El silencio y la indiferencia son aliados nocivos en la defensa de los derechos humanos.

La estimulación de la negación de lo que significa ser un otro diferente y que se expresa a través de hechos secuenciales de violencia sicológica, moral y física tienen su génesis en 
actitudes prejuiciosas que si son potenciadas se convierten en actos prejuiciosos que derivan en discriminación. Si los actos discriminatorios son respaldados por el establishment se transforman en actos de violencia que de no ser intervenidos terminan en genocidios, asesinatos... Shoá. Esto se conoce como la pirámide del odio, concepto que

debe ser abordado en todos los niveles de formación ciudadana. Por lo mismo cabe preguntar: ¿Contempla el Eje de Formación Ciudadana estos elementos de reflexión para con los estudiantes? Y de ser así, ¿Cuál es la magnitud del análisis esperado?

La educación es un puente que permite brindar espacios referenciales; es el motor que en este caso nos entrega lugares comunes de acogida y de accionar conocimiento. Educar en Holocausto también entrega la posibilidad de transmitir a los estudiantes la mirada de renacimiento y replanteamiento que es parte del ciclo de la vida. Así como hubo perpetradores y observadores pasivos también hubo muchas personas que frente al dilema de observar y callar optaron por accionar y ejecutar. Este concepto de Justo entre las Naciones es aplicable a cualquier persona que, en un momento extremo como Shoá, sea capaz de traspasar las barreras de lo estatuido para demostrar lo que significa actuar en base a lo correcto.

\section{Propuesta de Didácticas Integradas: Análisis de una experiencia escolar a través de la implementación de Shoá en el currículum de 4to a 8vo básico.}

Una Unidad Didáctica Integrada es un instrumento de planificación que busca generar a través del desarrollo de proyectos educativos experiencias de aprendizajes significativas basadas en la trasposición didáctica, la concreción curricular y la valoración de aprendizajes. Para ello se realiza una propuesta pedagógica que enfatiza el desarrollo de competencias vinculadas a un contexto con tareas determinadas.

Para poder llevar a cabo esta propuesta es necesario contar con la construcción de un currículum integrado que contemple la incorporación de varias asignaturas con tiempos acotados a la tarea establecida para un conjunto específico de estudiantes. La idea es propiciar al estudiante de recursos que le permitan generar una práctica reflexiva frente al 
sistema de valores inserto en cada acto de aprendizaje y así mismo desarrollar destrezas para establecer relaciones e interacciones con los contenidos propuestos y con otros.

A modo de ejemplo, la escuela República de Israel de Santiago diseña e implementa en su currículum formal el proyecto Identidad, Memoria y Shoá como una apuesta de instalación pedagógica cuyo objetivo general señala:

"Incorporar en el curriculum escuela el concepto de Shoá para así generar espacios educativos de reflexión que permitan por un lado difundir en la comunidad escolar las causas y consecuencias de la Shoá en la vida del pueblo judío y por otro establecer las bases cívicas de construcción de identidad basadas en el respeto por la vida y los derechos humanos”.

Así mismo, se plantearon objetivos específicos destinados a potenciar la identidad de los actores educativos y su pertenencia con el establecimiento y validar el concepto de educación por la paz.

La metodología de trabajo contempla la organización de las actividades en el primer y segundo semestre del año en curso, siendo el primer semestre dedicado a la capacitación docente a través de 6 talleres desarrollados entre los meses de Mayo y Junio a cargo de la Fundación para la Preservación de la Memoria Judía en Chile y el segundo semestre se focaliza en la intervención curricular de la unidad pedagógica Identidad, Memoria y Shoá en los cursos de 4to a 8vo básico en las asignaturas de Historia, Geografía y Ciencias Sociales, Arte, Lenguaje y Religión Católica y Evangélica empleando para ello la modalidad UDI (Unidad de Didácticas Integradas) y la metodología Yad Vashem para la enseñanza de la Shoá.

En relación a la selección del contenido de aprendizaje para ser trabajado con las profesoras escuela se presenta la unidad ¿Cómo fue Humanamente Posible? Ésta relata un viaje profundo y esclarecedor de lo que significó la Shoá para el pueblo judío. A través del uso de la metodología Yad Vashem, las profesoras expositoras presentan la secuencia histórica 
del antes, durante y después de Shoá empleando, además, la didáctica del uso de dilemas y preguntas poderosas para generar discusión y pensamiento crítico frente a la temática expuesta.

En el caso de los contenidos a ser desarrollados con los alumnos, en un principio se propone presentar la temática "Los Niños y La Shoá” por ser ésta cercana a sus rangos de edad, sin embargo, el equipo de trabajo compuesto por las docentes escuela decide focalizarse en los hechos acaecidos en los Guetos de Lodz y de Varsovia por su significancia histórica y simbólica. Por lo tanto, los cuartos básicos son introducidos a la historia del Gueto de Lodz, los quintos y sextos básicos estudian el Gueto de Varsovia desde la perspectiva del antes, la vida, tradición y costumbres; los séptimos y octavos básicos realizan un recorrido por la vida judía durante la Shoá en el Gueto de Varsovia y el levantamiento ocurrido en éste.

Si bien, el proyecto contemplaba realizar una exposición con una muestra de trabajos que evidenciara el aprendizaje de los estudiantes como finalización de la actividad en el propio establecimiento, finalmente el cuerpo docente a cargo de éste decide evidenciar los conocimientos adquiridos mediante una instalación urbana artístico cultural en la Plaza Yungay llamada Camino de Libertad y Esperanza liderada por los alumnos quienes hacen las veces de compañeros de viaje y expositores.

Esta apuesta consta de 8 intervenciones localizadas en el perímetro completo de la Plaza Yungay. Cada rincón se convierte en una estación que representa o simboliza el camino recorrido por los judíos desde la opresión y la persecución hasta la liberación y la reconstrucción de una nueva vida.

El recorrido parte con la instalación "El Pianista de Varsovia". En ella se instala un piano con el rostro de las personas que vivieron en el gueto. Los rostros son dibujados con notas musicales.

A su vez se diseñan tres atriles donde se presentan las historias y testimonios para que la gente se acerque a sus vidas. 
La segunda estación se llama "Si el Grano de Trigo no Muere". Está intervención está constituida por 16 cajones de madera (fruta) donde se coloca tierra pintada con color negro. En éste se pondrá por parte del público palitos con los nombres de las personas que fueron asesinadas en el gueto. Para esto, cada persona que asiste recibe dos nombres. Uno es colocado en la tierra y otro se guarda hasta una siguiente intervención.

El tercer hito se denomina “Trenes y Maletas". Se muestra un tren realizado por los niños y niñas de la escuela de 15 metros de largo. Se ubica en forma circular y alrededor de él se localizan algunas maletas antiguas con prendas de ropa y cartas con testimonios que podrán ser leídas por los que participen de las intervenciones. La idea es que las propias maletas sean las que hablen.

La cuarta intervención se llama "Volantines en el Campo". Esta intervención que contiene 15 metros de alambre de púa, colocados en el suelo de manera serpenteada. Ahí los visitantes pueden leer poemas escritos por los niños y niñas de segundo ciclo. Esta instalación busca mostrar los primeros aires de libertad.

La quinta instalación es "Diarios de Vida". Ésta consta de algunas mesas antiguas y sillas donde se colocan diarios de artistas. Éstos tienen escrito en sus primeras páginas algún hecho ocurrido en el campo de concentración. La idea es invitar a los asistentes a seguir escribiendo el diario ya sea a través de un mensaje al autor del texto principal o lo que a ellos les evoque estos textos.

La sexta intervención lleva por nombre "Sembrando Esperanza". A una altura equidistante de la segunda intervención, se realiza su respuesta artística. Una construcción de 16 cajones de madera, en igual disposición espacial que la anterior ( $\mathrm{Si}$ el grano de trigo no muere) donde se coloca el nombre de la persona que les tocó en un inicio y se sembrarán semillas.

La séptima intervención se denomina "Cartas al Cielo". El objetivo de esta actividad es colgar de los árboles hilos encerados, desde donde se ubican sobres de colores. La idea es que el público pueda escribir una carta, colocarla en un sobre y colgarla en los árboles.

La última estación es “Zapatos de Colores”. Ésta se realiza en el perímetro circular de la plaza, (sólo en una parte de ella) donde se colocarán pares de zapatos, pintados por los 
estudiantes, con una idea o palabra escrita por ellos. Esta actividad marca el fin de la muestra y del camino.

Para la comunidad educativa el levantamiento de esta propuesta pedagógica centrada en derechos humanos a través de la incorporación de una educación basada en el Holocausto (Shoá) marca un antes y un después. El impacto provocado en la formación moral y valórica de los estudiantes generó que a nivel aula se gestaran espacios de reflexión tendientes a analizar fenómenos actuales con una mirada de memoria y legado.

La planificación sistemática de la unidad "Identidad, Memoria y Shoá" y su consecutiva realización en el proyecto "Camino de Libertad y Esperanza" son una muestra de las posibilidades que existen de abordar el currículum dentro de su ductilidad. La incorporación de una unidad centrada en didácticas integradas abrió espacios dialógicos no abordados hasta ahora en el establecimiento. Esto reviste un desafío y un replanteamiento de la senda a seguir para impactar positivamente en el aprendizaje de los alumnos frente a las dinámicas de didácticas pedagógica actuales. Por lo mismo, esta apuesta abre la puerta que instala a la escuela en la génesis que le corresponde: un agente de cambios que impacta el contexto social donde se encuentra.

Sin duda alguna, una de las fortalezas presentadas por este proyecto y su concreción mediante la incorporación de las didácticas integradas permitió potenciar el liderazgo pedagógico colaborativo distribuido entre los docentes y centrar las prácticas pedagógicas en el estudiante como constructor de su conocimiento y sujeto activo de aprendizaje. Esto significa que son los propios docentes, quienes a través de su conocimiento y visión pedagógica, los que finalmente articulan la decisión del desarrollo del tema y la concreción del proyecto. Esto reviste de un valor enorme puesto que aun cuando el proyecto es presentado desde la dirección del establecimiento son ellos los que colectivamente y colaborativamente le dan vida.

Para los profesores de la escuela E.50 República de Israel, el proceso de formación en Shoá marca un antes y un después no solamente frente a los conocimientos adquiridos sino que también frente al desarrollo de identidad y compromiso con la comunidad educativa y el establecimiento. Por lo mismo, el equipo de gestión realizó un análisis centrado en la 
articulación que este proyecto en particular tiene con en el Proyecto Educativo y El Plan de Formación Ciudadana escuela. Lo último referido a las alternativas que como escuela se gestan para trabajar los valores de formación distintivos de la Misión y la Visión Institucional.

La puesta en escena del proyecto final generó en toda la comunidad educativa docente la convicción de que se había apostado por un acto de valentía dado que se trabajó una temática no abordada por ningún otro establecimiento público del país. Además, este hecho ha sido catalogado como un hito en la historia de la escuela y son los mismos docentes quienes han propuesto poder compartir esta experiencia con otras comunidades educativas.

Sin embargo, el desafío que se presenta a la gestión institucional es mantener esta iniciativa como parte del constructo educativo y replicarlo en otros contextos escolares como una herramienta de gestión pedagógica centrada en la pedagogía de la memoria y derechos humanos para así instalar una práctica que defina el sello identitario del establecimiento.

\section{Conclusiones.}

La educación en derechos humanos es una responsabilidad que los gobiernos deben asumir como la herramienta que permite establecer lineamientos de formación centrados en inclusión, respeto, validación por la persona humana y por la condición humana.

Desde una perspectiva axiológica se hace complejo el poder comprender cuáles son las razones que motivan a los seres humanos a decidir homogeneizar los constructos sociales, políticos y económicos por la fuerza. En este aspecto, las dignidades individuales se ven mermadas por las necesidades colectivas y esto finalmente repercute en las decisiones irracionales ejecutadas por los poderes fácticos.

Una forma de violación del derecho de cualquier individuo y en cualquier sociedad es el uso de la educación de su pueblo como agente de proselitismo y manipulación. En este aspecto, es interesante observar la forma en como los regímenes totalitarios han empleado el acto educativo para la concientización y el adoctrinamiento. Un claro ejemplo de ello es la propaganda educativa y visual empleada por los Nazis para educar a la población frente 
al mal llamado judío. ¿No es acaso esta forma la replicada por otros Estados para fomentar la discriminación y expandir en sus ciudadanos la pirámide del odio? ¿Cuáles son, entonces, los precedentes que se deben tomar en consideración a la hora de proclamar inclusividad en sociedades con tendencias separatistas?

El Estado Chileno ha declarado ex profeso defender el resguardo de los derechos humanos a través de la incorporación al currículum de Historia, Geografía y Ciencias Sociales del Eje de Formación Ciudadana. Así mismo, en un acto heroico se promulga en 2016 la Ley que demanda a todos los establecimientos educacionales públicos contar con un Plan de Formación Ciudadana. Este acto responde a un largo silencio político, a largas discusiones de posturas frente a lo que significa la responsabilidad educativa en la formación de los futuros actores sociales de la nación.

Por consiguiente, la propuesta del presente trabajo estableció determinar la responsabilidad que recae en las instituciones de enseñanza básica la transmisión de la memoria basada en derechos humanos y Shoá.

Para dar respuesta a esta interrogante se determinan tres líneas de análisis. La primera se enmarca en "Memoria y Legado". En ella se expone el concepto de Pedagogía de Memoria y su implicancia en la formación estudiantil y docente como instrumento de comprensión de fenómenos históricos. Se hace hincapié, además, a que los derechos humanos no pueden ser tratados si no van acompañados por hitos de memoria puesto que este referente es el que finalmente genera legado y aprendizaje.

A su vez, el segundo punto se centra en "Educación en Derechos Humanos y Shoá". Este apartado expone la consecución de eventos referidos a la incorporación de la temática de derechos humanos en el currículum nacional. Al mismo tiempo se presenta una breve reseña del Eje de Formación Ciudadana desde 4to a 8vo básico. Esta información se sustenta con lo establecido en la Ley 20.911 Plan de Formación Ciudadana. Finalmente, a través de un relato histórico y de memoria, se establecen los lineamientos que justifican la incorporación de la Shoá al currículum de enseñanza de derechos humanos. 
El tercer apartado describe la experiencia pedagógica de la incorporación al currículum escuela, a través de la implementación de las didácticas integradas, la temática del Holocausto como un recurso pedagógico para la enseñanza de derechos humanos.

Si bien es cierto el eje de formación ciudadana de 4to a 8vo básico da respuesta a la necesidad país de incorporar temáticas referidas al desarrollo del sentido de pertenencia identitaria y actos de empoderamiento ciudadano, carece de un enfoque pedagógico basado en memoria que permitan ejercitar el pensamiento crítico ético y moral con ejemplos de problemáticas reales que ponen a prueba el dilema de la aceptación o negación de actos que vulneran los derechos humanos. Esto es preocupante dado que educación básica sienta los pilares formativos de vida.

De la misma manera, el contar con una ley que promueva la reivindicación del accionar ciudadano a partir de la creación autónoma de Planes de Formación Ciudadana tiene la desventaja de sesgar miradas puesto que cada establecimiento educacional posee un Proyecto Institucional único, lo que significa excluir posturas y lineamientos en un discurso inclusivo.

Finalmente, a la luz de lo expuesto anteriormente educar en Shoá permite por una parte acercar tanto a profesores como a estudiantes al paradigma de la inclusión y de exclusión, la integración y la segregación en contextos de diversidad e interculturalidad. Además, genera un lenguaje que establece con claridad las responsabilidades frente al actuar de perpetradores, observadores pasivos y justos. La pedagogía en Shoá abre un espacio de análisis frente al silencio colectivo, la pasividad y la indiferencia dado que Shoá es el resultado de un acto de discriminación de minorías. Por ende, el currículum será enriquecido con su implementación y la vida de los estudiantes transformada. El ejercicio de memoria busca un nunca más; a través de esta apuesta se pretende potenciar el desarrollo del pensamiento crítico que estimule la formación de seres humanos conscientes de su actuar y como éste repercute en los otros.

\section{Bibliografía}


BAUER, Yeuda. Reflexiones sobre el Holocausto. E.D.Z. Nativ Ediciones, Jerusalén. 2013. 356p.

GUTMAN, Israel. Holocausto y Memoria. Centro Zalman Shahar de Historia Judía. Yad Vashem. Jerusalén. 2013. 400p.

IZQUIERDO, Teresa. El Lugar de la Memoria en la Educación Pública. Una Política Para el Olvido. Cuadernos de Trabajo Educativos. Área de Educación. Corporación Parque por la Paz Villa Grimaldi. Año III. Volumen VII. <http://villagrimaldi.cl/wp-content/uploads/2011/07/Cuaderno_vii.pdf >. [consulta: 09 de diciembre de 2017]

MAGENDZO, Abraham y TOLEDO, María Isabel. Educación en Derechos Humanos: Curriculum en Historia y Ciencias Sociales del $2^{\circ}$ año de Enseñanza Media. Subunidad "Régimen Militar y Transición a la Democracia”. Estudios Pedagógicos. Versión Online. XXXV, N¹. $2009 . \quad<$ http://www.scielo.cl/scielo.php?pid=S0718-07052009000100008\&script=sci_abstract> $>$ [consulta: 09 de diciembre de 2017]

SACAVINO, Susana. Pedagogía de la Memoria y Educación para el Nunca Más para la Construcción de la Democracia. [en línea]. En Folios. Segunda Epoca. $N^{\circ} 41 . \quad 2015$. <http://revistas.pedagogica.edu.co/index.php/RF/article/view/2946>. [consulta: 08 de diciembre de 2017]

Declaración Universal de los Derechos Humanos. [en línea]. 〈http://www.derechoshumanos.net>. 10 de diciembre de 1948.

Ley 20.370. General de Educación. [en línea]< http://www.leychile.cl>, Santiago, Chile, 12 de septiembre de 2009.

Ley 20.911 Plan de Formación Ciudadana para los Establecimientos Educacionales Reconocidos por el Estado. [en Línea]. 〈https://www.leychile.cl/Navegar?idNorma=1088963>. Santiago, Chile, 02 de abril de 2016. [consulta: 08 de diciembre de 2017].

Mineduc, Historia, Geografía y Ciencias Sociales. Programa de Estudio Sexto Año Básico. [en línea]. <http://www.curriculumenlineamineduc.cl/605/articles-18973_programa.pdf.> [consulta: 08 de diciembre 2017].

Mineduc, Eje de Formación Ciudadana. [en línea]. <https://formacionciudadana.mineduc.cl/formacionciudadana-curriculum/modulos-didacticos-eje-formacion-ciudadana/ > [consulta: 08 de diciembre 2017]. 